\title{
INFLUÊNCIA DE DESFOLHAS ARTIFICIAIS PARA SIMULAR PERDAS NA PRODUÇÃO DO FEIJOEIRO (PHASEOLUS VULGARIS L. CV. XAMEGO)
}

\author{
E.R. Schmildt' ${ }^{1}$, J.A.T. do Amaral ${ }^{2}$, D. Pratissoli ${ }^{2}$, E.F. dos Reis ${ }^{2}$ \\ ${ }^{1}$ Universidade Federal do Espírito Santo, Centro Universitário do Norte do Espírito Santo, R. Humberto de \\ Almeida Franklin, 257, CEP 29933-415, São Mateus, ES, Brasil. E-mail: edilson@npd.ufes.br
}

\section{RESUMO}

A redução da área foliar é uma das causas da queda de produção em feijoeiro comum. O objetivo deste trabalho foi verificar a influência de diferentes níveis de desfolha em vários estádios de desenvolvimento sobre a produtividade, massa de 100 sementes e número de vagens por planta do feijoeiro da cultivar Xamego, em condições de campo no Sul do Espírito Santo. Utilizou-se o delineamento em blocos casualizados, sendo as parcelas dispostas no esquema fatorial $5 \times 4$ : cinco épocas de desfolha ( $1^{\mathrm{a}}$ folha trifoliolada, florescimento, formação das vagens, enchimento das vagem, e vagens secas) x quatro níveis de remoção das folhas (0, 33, 67 e 100\%), com cinco repetições. Houve decréscimo linear da produtividade com os níveis de desfolha em todos os estádios de desenvolvimento, com exceção ao de vagens secas, sendo este decréscimo maior no estádio de formação das vagens. Pela análise de regressão atribui-se maior redução da produtividade com 100\% de desfolha feita aos 44 dias após emergência. O componente de rendimento mais correlacionado com a produtividade foi o número de vagens por planta.

PALAVRAS-CHAVE:Feijoeirocomum, desfolhamento, produtividadedegrãos, massa degrãos, vagens.

\section{ABSTRACT}

INFLUENCE OF ARTIFICIAL DEFOLIATION TO SIMULATE LOSSES IN PRODUCTION OF BEANS (PHASEOLUS VULGARIS L. CV. XAMEGO). The reduction of foliar area can cause yield reduction in common bean crops. The objective of this work was to ascertain the effect of different defoliation levels realized in several developmental stages of common beans (Phaseolus vulgaris L. cv. Xamego) in regard to yield, weight of 100 seeds and number of pods per plant. A randomized complete block design was used considering a two-way $5 \times 4$ factorial arrangement: (i) five defoliation stages (first trifoliate leaf, flowering, pods formation, pods filling, and dry pods), and (ii) four defoliation levels (0, 33, 67 and 100\%). Five replications were carried out. A linear decrease of yield was observed for all defoliation levels considering all development stages, except for dried pods. The highest decrease was detected for pods formation. At $100 \%$ of defoliation, a higher decrease of yield was observed when it was done at 44 days after emergence. Regression analysis gave a greater reduction in yield with $100 \%$ defoliation done at 44 days after emergence. The evaluation parameter that showed the best correlation with yield was the number of pods per plant.

KEY WORDS: Common bean, defoliation, yield, seed weight, pods.

\section{INTRODUÇÃO}

O feijoeiro comum é cultivado em várias regiões fisiogeográficas brasileiras, existindo cultivares adaptadas às mais diversas condições ecológicas (AIDAR, 2003; EMBRAPA, 2009; BAHIA, 2009). O feijoeiro Xamego é recomendado para o plantio nos estados de Goiás, Espírito Santo, Rio de Janeiro e no Distrito Federal (EMBRAPA, 2009), apresentando-se como um dos mais promissores para o Sul do Estado do Es- pírito Santo (MarTins FilHo et al., 2001; AltoÉ, 2007; MORAEs et al., 2008).

O cultivo do feijoeiro, em diversificados sistemas de produção, numa grande diversidade de ecossistemas (AIDAR, 2003; BAHIA, 2009), faz com que alguns fatores tornem-se limitantes à sua produção. No Brasil, reduções na produção de feijoeiro são causadas principalmente pelos coleópteros Diabrotica speciosa, Cerotoma sp. (vaquinhas) e Lagria vilosa (idi-amim), e pelos lepidópteros Hedylepta indicata (lagarta en-

${ }^{2}$ Universidade Federal do Espírito Santo, Centro de Ciências Agrárias, Alegre, ES, Brasil. 
roladeira de folhas), Pseudoplusia includens (lagarta mede palmo) e Urbanus proteus (lagarta cabeça de fósforo), em decorrência da redução da área foliar (BATISTA et al., 1992). Uma população elevada de insetos desfolhadores pode promover queda na produção de feijoeiro de 11 a 100\%, dependendo da cultivar (QUINTELA, 2009), especialmente se a ocorrência coincidir com o período da germinação até o florescimento (BATISTA et al., 1992). Isso porque a produção está diretamente relacionada à capacidade fotossintética das plantas e, portanto, na dependência do índice de área foliar (WATSON, 1947). Assim, plantas submetidas à desfolha podem ter a produção reduzida, principalmente em decorrência da diminuição no número de vagens (BORTOLI et al., 1983; XIA, 1993; Moura, 1999) e no peso dos grãos (HoHManN; CARVAlHo, 1982).

Ofeijoeiro comumé também atacado por doenças causadas por fungos, bactérias e vírus (BAHIA, 2009), que causam quedas de folhas (GIANASI, 2002), mas a cultivar Xamego apresenta níveis de resistência a várias doenças tais como antracnose, ferrugem, mosaico comum e à murcha de Fusarium, sendo susceptível à mancha angular, crestamento bacteriano comum e mosaico dourado (EMBRAPA..., 2009).

$\mathrm{O}$ efeito significativo na perda do rendimento de grãos na colheita varia em virtude da época e da intensidade da desfolha (EDJE et al., 1972; BORTOLI et al., 1983; SchaAfsma; Ablett, 1994; Moura, 1999; PRATISSOLI et al., 2001), havendo, portanto, uma estreita inter-relação entre produção e desfolha, dependendo do estádio de desenvolvimento das plantas (Silva et al., 2003). Todavia, os resultados de trabalhos que apontam a época de desfolha mais prejudicial para a cultura do feijoeiro são bastante contrastantes. HohmanN; CarvalHo (1982) e Moura; MesQuita (1982) observaram maiores danos à cultura quando as desfolhas foram realizadas no início da formação de vagens. BORTOLI et al. (1983) e MourA (1999) constataram ser o florescimento o estádio mais prejudicial. SiLva et al. (2003), no entanto, observaram que a desfolha de $25 \%$ em plantas com 10 e 17 dias de idade não diminuiu significativamente a produção, mas em plantas com mais de 24 dias de idade a desfolha em todos os níveis reduziu a produção do feijoeiro. Outros autores (GÁlvEZ et al., 1977; XIA, 1993; SCHAAFSMA; ABLETT, 1994) concluíram não existir um estádio mais prejudicial e sim, um período, que vai da floração ao enchimento das vagens. Contudo, não se dispõe de informações sobre os níveis de redução da área foliar do feijoeiro da cultivar Xamego, frente às desfolhas provocadas, sobretudo por insetos pragas, que ocasionam perdas significativas na produção de grãos nas condições do Sul do Estado do Espírito Santo.

O objetivo deste trabalho foi verificar o efeito de diferentes níveis de desfolha artificial do feijoeiro cultivar Xamego, em diferentes estádios de desenvolvimento das plantas, cultivadas em condições de campo, no Sul do Estado do Espírito Santo, sobre a produção de grãos, número de vagens planta $^{-1} \mathrm{e}$ massa de 100 sementes.

\section{MATERIAIS E MÉTODOS}

O trabalho foi realizado na área experimental de Rive do Centro de Ciências Agrárias da Universidade Federal do Espírito Santo (CAA-UFES), localizada em Alegre, ES (Latitude: $20^{\circ} 45^{\prime}$ S; Longitude: $41^{\circ} 29^{\prime} \mathrm{W}$; Altitude: $150 \mathrm{~m}$ ), durante os meses de outubro a dezembro de 2003, com a cultivar de feijoeiro Xamego, grupo preto.

O solo onde foi implantado o experimento é do tipo Argissolo Vermelho (EMBRAPA..., 1999) e encontrava-se com as seguintes características químicas: $\mathrm{pH}=6,9 ; \mathrm{Al}^{+3}=0,0 \mathrm{cmol}_{\mathrm{c}} \mathrm{dm}^{-3} ; \mathrm{Ca}^{+2}=3,7 \mathrm{cmol}_{\mathrm{c}} \mathrm{dm}^{-3}$; $\mathrm{Mg}^{+2}=1,6 \mathrm{cmol}_{\mathrm{c}} \mathrm{dm}^{-3} ; \mathrm{P}=12 \mathrm{mg} \mathrm{dm}^{-3} ; \mathrm{K}=90 \mathrm{mg}$ $\mathrm{dm}^{-3}$. Não foi realizado qualquer tipo de adubação durante a condução deste trabalho, por estarem os níveis nutricionais adequados para a cultura do feijoeiro (DADALTO; Fullin, 2001).

O delineamento experimental foi o de blocos ao acaso no arranjo fatorial $5 \times 4$ com cinco repetições. $O$ primeiro fator foi composto por cinco épocas de desfolha (FERNÁNDEZ et al., 1985): V3 - 1ª folha trifoliolada (aos 15dias após emergência), R6 - florescimento (aos 30 dias após emergência), R7 - formação das vagens (aos 45 dias após emergência), R8 - enchimento das vagens (aos 60 dias após emergência) e R9 - vagens secas (aos 75 dias após emergência); o segundo fator foi composto por quatro níveis de desfolha: $0 \%$, $33 \%, 67 \%$ e $100 \%$ de remoção das folhas trifolioladas. Cada parcela foi composta de duas fileiras de $3 \mathrm{~m}$ de comprimento. $\mathrm{O}$ espaçamento utilizado foi de $0,5 \mathrm{~m}$ entre linhas e 0,10 $\mathrm{m}$ entre plantas. Como bordaduras foram utilizadas duas fileiras da cultivar Capixaba Precoce, semeadas no mesmo espaçamento das parcelas, ao redor de cada bloco.

Para obtenção dos níveis de desfolha, a retirada manual dos folíolos obedeceu ao seguinte padrão para todas as épocas de remoção: 1) planta sem desfolha; 2 ) planta com $33 \%$ de desfolha (retirada de 1 folíolo por folha); 3) planta com $67 \%$ de desfolha (retirada de 2 folíolos por folha); 4 ) planta com $100 \%$ de desfolha (retirada de todos os folíolos). As desfolhas foram realizadas manualmente, sem a utilização de qualquer instrumento cortante.

Os tratos culturais empregados foram os comumente recomendados para a cultura do feijoeiro. Foram feitas irrigações por aspersão durante todo o ciclo da cultura de modo a manter o solo da área experimental na capacidade decampo. Pulverizações com inseticida e fungicida foram feitas preventiva- 
mente, para evitar a ação de pragas ou doenças que viesse a reduzir a área foliar, já que esta deveria ser feita apenas de maneira artificial, de acordo com os tratamentos. Os inseticidas usados foram à base de trichorfon (800 gramas por hectare), aplicado aos 10 e 40 dias após a semeadura, e de methamidaphós (400 gramas por hectare), aplicado aos 25 e 55 dias após semeadura. Os fungicidas usados foram à base de chlorothalonil (70 gramas por 100 litros de água), aplicado aos 10 e 40 dias após semeadura, e óxido cuproso (107 gramas por 100 litros deágua), aplicado aos 25 e 55 dias após semeadura.

As plantas ao serem colhidas, aos 90 dias após a semeadura, foram separadas por parcela e avaliadas as seguintes variáveis: número de vagens por planta, massa de 100 sementes, produtividade, em g parcela ${ }^{-1}$, que posteriormente foi convertida em $\mathrm{kg}$ ha ${ }^{-1}$ para análise estatística.

As médias das variáveis foram analisadas estatisticamente pelo teste $\mathrm{F}$, regressão e correlação de Pearson. Todas as análises foram feitas utilizando-se o programa GENES (CRUZ, 2001).

\section{RESULTADOS E DISCUSSÃO}

Houve diferença significativa entre as médias dos estádios de desenvolvimento (ED) e dos níveis de desfolha (ND) e da interação entre esses fatores para as variáveis produtividade e número de vagens por planta. Quanto à variável massa de 100 sementes houve diferença significativa apenas para ND (Tabela 1).

A produtividade sofreu influência dos ND em todos os estádios de desenvolvimento, seguindo um modelo linear, com exceção ao R9 (vagens secas) (Fig. 1). Nota-se que as desfolhas foram mais prejudiciais no estádio R7 (formação das vagens) com redução de produtividade de cerca de $80 \%$. Esses resultados são semelhantes aos observados por outros pesquisadores em outras cultivares (Hohmann; CARvalHo, 1982; Moura; Mesquita, 1982; Pratissoli et al., 2001), e difere dos resultados observados por FAzOLIN; EsTRELA (2003), com a cultivar Pérola e, por Moura (1999), com cultivares Carioca e Rosinha, em que a desfolha no estádio R6 (florescimento) provocou as maiores reduções na produção. Em outros estudos não foram encontrados um estádio mais prejudicial para o desfolhamento do feijoeiro e sim um período de maior dano, que vai do florescimento até enchimento de vagens, quando ocorreram as maiores perdas na produção ( GÁLVEZ et al., 1977; SchAAFSMA; AвLETt, 1994). As variações de respostas ao desfolhamento verificadas em diversas pesquisas demonstram a variabilidade dos genótipos e não se devem extrapolar os resultados para as diferentes cultivares existentes.

Tabela 1 - Resumo da análise de variância para as variáveis produtividade, massa de 100 sementes e número de vagens por planta na cultivar Xamego influenciada por quatro níveis de desfolha (ND) em cinco estádios de desenvolvimento(ED)

\begin{tabular}{|c|c|c|c|c|c|c|c|}
\hline \multirow{2}{*}{ F. V. } & \multirow{2}{*}{ G. L. } & \multicolumn{6}{|c|}{ Quadrado médio } \\
\hline & & \multicolumn{2}{|c|}{ Produtividade $\left(\mathrm{kg} \mathrm{ha}^{-1}\right)$} & \multicolumn{2}{|c|}{ Massa de 100 grãos (g) } & \multicolumn{2}{|c|}{ Vagens por planta $\left(\mathrm{n}^{\circ}\right)$} \\
\hline Bloco & 4 & 1169953,56 & & 6,1809 & & 4,8674 & \\
\hline $\mathrm{ED}$ & 4 & 1063802,25 & $* *$ & 8,6112 & ns & 34,6031 & $* *$ \\
\hline ND & 3 & 4433612,89 & $* *$ & 25,3905 & $* *$ & 36,1163 & $* *$ \\
\hline $\mathrm{ED} \times \mathrm{ND}$ & 12 & 619561,76 & $* *$ & 4,4445 & ns & 18,2393 & $* *$ \\
\hline Erro & 76 & 137831,29 & & 5,3689 & & 2,8959 & \\
\hline Média & & 1890,31 & & 19,39 & & 11,91 & \\
\hline $\mathrm{CV}_{(\%)}$ & & 19,64 & & 11,95 & & 14,29 & \\
\hline
\end{tabular}

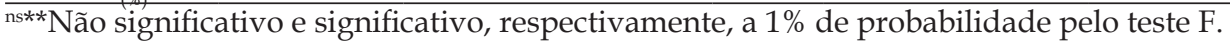

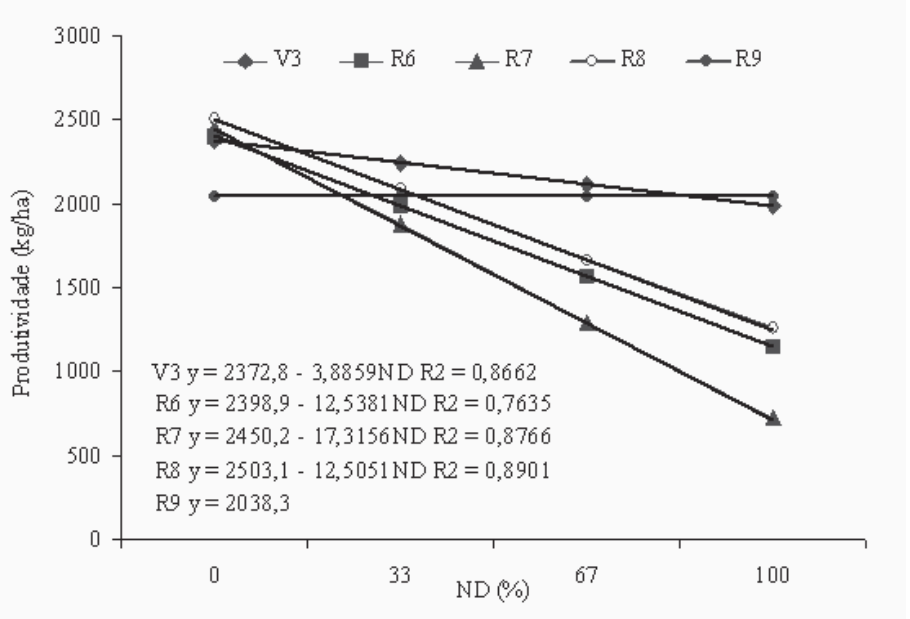

Fig. 1 - Produtividade da cultivar de feijoeiro Xamego em função dos níveis de desfolha (ND, $\%)$ aplicados em diferentes estádios de desenvolvimento (V3, R6, R7, R8 e R9, correspondentes a, respectivamente, 15, 30, 45, 60 e 75 dias após a germinação). 
A produtividade em função dos ED equivalente em dias após a emergência (DAE) seguiu o modelo quadrático (Fig. 2). A maior perda de produtividade estimada $(85,7 \%)$ ocorreu com $100 \%$ de desfolha feita aos 44 DAE. Com $67 \%$ de desfolha, as maiores perdas de produtividade $(34,3 \%)$ ocorreram também aos $44 \mathrm{DAE}$. A perda de área foliar no feijoeiro afeta os componentes do rendimento, em razão das alterações provocadas na atividade fisiológica das plantas, influenciando finalmente na produtividade da cultura (Moura, 1999; Peterson et al., 1998).

A massa de 100 sementes em função do ND demonstrou seguir o modelo quadrático (Fig. 3). Pode-se constatar que a maior redução ocorre com $100 \%$ de desfolha. A redução da massa de grãos em função das desfolhas em feijoeiro também foi observada por outros pesquisadores (HOHMANN; CARVALHO, 1982; Bortoli et al., 1983; SCHAAFSMA; Ablett, 1994). A retirada de folhas e consequente redução da área fotossinteticamente ativa certamente provoca redução nos componentes de rendimento, por diminuição na quantidade defotoassimilados produzidos. PETERSON et al. (1998) relataram que a redução de área foliar de feijoeiro causada pelo coleóptero Epilachna varivestis provoca diminuição da taxa fotossintética nas plantas, associada principalmente com a utilização de fosfato e necessidade de regeneração da ribulose 1,5 bifosfato carboxilase (Rubisco).

O número de vagens por planta foi afetado pelos ND nos estádios de desenvolvimento R7 e R6 seguindo um modelo linear (Fig. 4). Nessas condições, o desfolhamento de 100\% representou redução de 64 e $41 \%$ do número de vagens nos estádios R7 e R6, respectivamente. BORTOLI et al. (1983), trabalhando com feijoeiro comum (cultivo de seca), verificaram perdas no número de vagens de $67 \%$, quando a desfolha foi realizada na época de floração (R6). O mesmo foi verificado por Pratissoli et al. (2001), que observaram reduções médias de 58,1 e 55,5\% do número de vagens para a cultivar Capixaba Precoce, quando aplicado o nível de desfolha de $100 \%$, sendo realizada nos estádios $R 6$ e $R 7$, respectivamente.
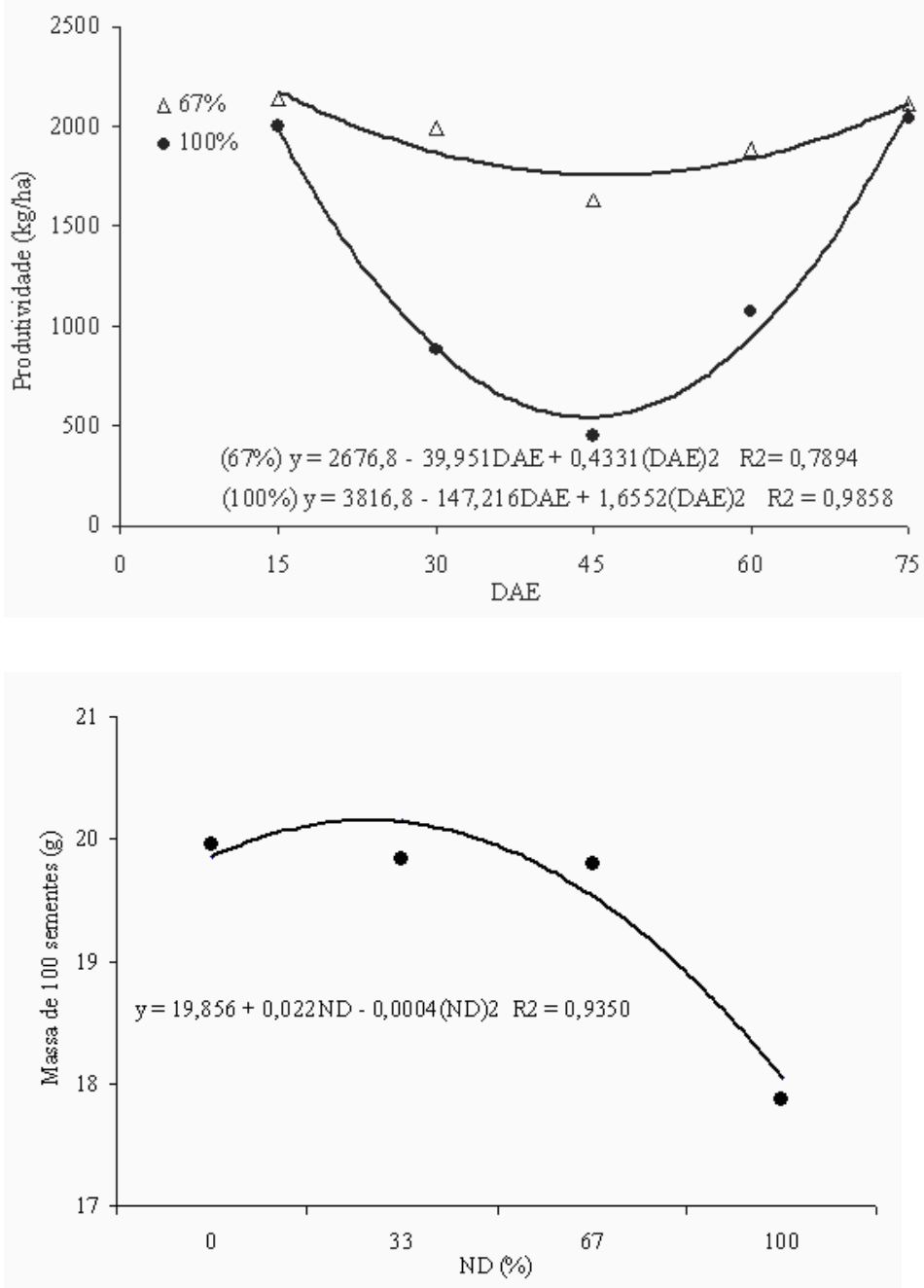

Fig. 2 - Produtividade da cultivar de feijoeiro Xamego para dois níveis de desfolha (67 e $100 \%)$ em cinco estádios de desenvolvimento (V3, R6, R7, R8 e R9), equivalente em dias após a emergência (DAE) em: 15, 30, 45, 60 e 75 dias, respectivamente.

Fig. 3 - Massa de 100 sementes da cultivar de feijoeiro Xamego em função dos níveis de desfolha. 

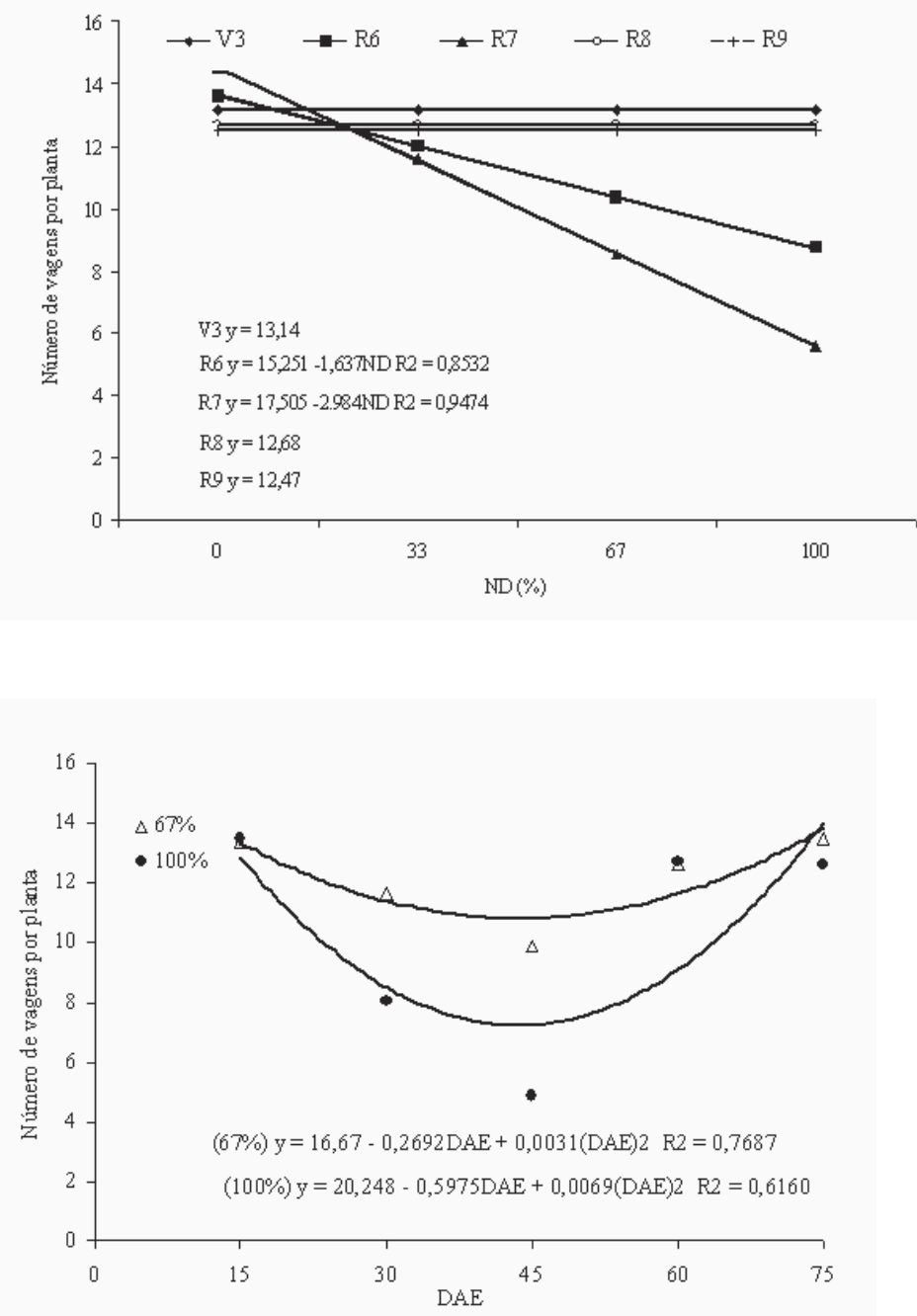

Fig. 4 - Número de vagens por planta da cultivar de feijoeiro Xamego em função dos níveis de desfolha (ND, \%) aplicados em diferentes estádios de desenvolvimento (V3, R6, R7, R8 e $\mathrm{R} 9$, correspondentes a, respectivamente, 15,30 , 45, 60 e 75 dias após a germinação).
Fig. 5 - Número de vagens por planta da cultivar de feijoeiro Xamego para dois níveis de desfolha (67 e 100\%) em cinco estádios de desenvolvimento (V3, R6, R7, R8 e R9), equivalentes em dias após a emergência (DAE) em: 15, 30, 45, 60 e 75 dias.

Tabela 2 - Estimativas dos coeficientes de correlação de Pearson entre as variáveis produtividade $\left(\mathrm{kg} \mathrm{ha}^{-1}\right)$, massa de 100 sementes (g) e número de vagens por planta.

\begin{tabular}{lccc}
\hline & Produtividade & Massa de 100 sementes & Número de vagens planta $^{-1}$ \\
\hline Produtividade & 1 & $0,6538^{* *}$ & $0,8404^{* *}$ \\
Massa de 100 sementes & & 1 & $0,2874^{\text {ns }}$ \\
Número de vagens planta ${ }^{-1}$ & & & 1 \\
\hline
\end{tabular}

ns**Não significativo e significativo, respectivamente, a $1 \%$ de probabilidade pelo teste $t$.

Sediyama et al. (1985), trabalhando com soja, relataram que, em razão do aumento do tamanho dos drenos nas épocas de florescimento e durante o enchimento das vagens, ocorrem picos de atividade fotossintética indicando maior necessidade de produtos fotossintéticos para a planta realizar sua função de produzir e encher vagens. Com as desfolhas ocorridas naquelas fases, houve maiores perdas no número de vagens, porque não ocorreu suficiente fotossíntese para a planta realizar essa função. Provavelmente, esteja acontecendo de modo semelhante com a cultivar Xamego, em virtude de limitações na disponibilidade de fotoassimilados, pelos decréscimos nas ralações fonte/dreno.
Com relação à ED, o número de dias após a emergência (DAE) explicou o número de vagens por planta segundo o modelo quadrático, quando as plantas foram submetidas à desfolha de 67 e 100\% (Fig. 5). O menor número de vagens por planta $(7,54)$ foi observado com $100 \%$ de desfolha aos 43 DAE. Reforça-se que a menor produtividade $(543,76 \mathrm{~kg}$ $\mathrm{ha}^{-1}$ ) foi obtida aos 44 DAE (Fig. 2), correspondente ao estádio R7. Isso evidencia que esse estádio é o mais crítico para o feijoeiro 'Xamego' e merece mais atenção por parte do produtor quanto ao controle de desfolhadores.

A correlação de Pearson entre as médias das variáveis analisadas (Tabela 2) demonstra que o 
componente de rendimento mais correlacionado à produtividade é o número de vagens por planta $(\mathrm{r}=0,8404)$, conforme já demonstrado para outros genótipos de feijoeiro (CoelHo et al., 2002).

\section{CONCLUSÕES}

Ocorre redução da produtividade com aumento dos níveis de desfolha em todos os estádios de desenvolvimento analisados, com exceção ao R9 (vagens secas), sendo este decréscimo maior no estádio de formação das vagens.As maiores reduções na produtividade e número de vagens por planta da cultivar Xamego ocorrem com intensidade de $100 \%$ de desfolhamento quando realizadas no estádio correspondente à formação de vagens.

O número de vagens por planta é o componente de rendimento mais correlacionado com a produtividade na cultivar Xamego.

\section{REFERÊNCIAS}

AIDAR, H. Cultivo do feijoeiro comum. Goiânia: Embrapa Arroz e Feijão, Sistema de Produção 2, 2003. Disponível em: <http:/ / sistemasdeproducao.cnptia.embrapa.br/ FontesHTML/Feijao/CultivodoFeijoeiro/index.htm>. Acesso em: 27 jan. 2009.

ALTOÉ, M. Comportamento de genótipos de feijoeiro sob cultivo orgânico. 2007. 63f. Dissertação (Mestrado em Produção Vegetal) - Universidade Federal do Espírito Santo, Alegre, ES, 2007.

BAHIA. Secretaria de Agricultura, Irrigação e Reforma Agrária. Cultura feijão. Disponível em: <http:/ / www. seagri.ba.gov.br/Feijao.htm\#Aspectos\%20Gerais>. Acesso em: 26 jan. 2009.

BATISTA, G.C. de; VENDRAMIN, J.D.; MARCHINI, I.C. Pragas do amendoim, feijoeiro e caupi - curso de entomologia aplicada à agricultura. Piracicaba: FEALQ, 1992. 760p.

BORTOLI, S.A. de.; NAKANO, O.; PERECIN, D. Efeitos de níveis de desfolhas e dobras artificiais de folíolos sobre a produtividade do feijoeiro (Phaseolus vulgaris) em cultura de seca. Anais da Sociedade Entomológica do Brasil, v.12, n.1, p.73-87, 1983.

COELHO, A.D.F.; FERNANDES, A.D.; CARDOSO, A.A.; CRUZ, C.D.; ARAÚJO, G.A. de A.; FURTADO, M.R.; AMARAL, C.L.F. Herdabilidade e correlações da produção do feijão e dos seus componentes primários, nas épocas de cultivo da primavera-verão e do verãooutono. Ciência Rural, v.32, n.2, p.211-216, 2002.

CRUZ, C.D. Programa GENES: aplicativo computacional em genética e estatística. Viçosa: UFV, 2001. 648p.
DADALTO, G.G.; FULLIN, E.A. Manual de recomendação de calagem e adubação para o Estado do Espírito Santo. $4^{a}$ aproximação. Vitória, ES: SEEA/INCAPER, 2001. 266p.

EDJE, O. T.; MUGHOGHO, L.K.; AYONOADU, E.U. Efect of leaf removal on the yield of Phaseolus beans. Malawi Journal of Science, v.1, n.1, p.10-14, 1972.

EMBRAPA (Brasil). Centro Nacional de Pesquisa de Arroz e Feijão Cultivar Xamego. Goiânia: Embrapa Arroz e Feijão. Disponível em: <http:/ / www.cnpaf.embrapa. br/feijao/xamego.htm>. Acesso em: 28 jan. 2009.

EMBRAPA (Brasil). Centro Nacional de Pesquisa de Solos. Sistema Brasileiro de Classificação de Solos. Brasília, DF: Embrapa Serviço de Produção de Informação, 1999. 412p.

FAZOLIN, M.; ESTRELA, J.L.V. Comportamento da CV. Pérola (Phaseolus vulgaris L.) submetida a diferentes níveis de desfolha artificial. Ciência e Agrotecnologia, v.27, n.5, p.978-984, 2003.

FERNÁNDEZ, F.; GEPTS, P.; LOPES, M. Etapas de desarollo en la planta de frijol. In: LÓPEZ, M; FERNÁNDEZ, F.; SCHOONHOVEN, A. (Ed.). Frijol: investigación y producción. Cali: PNUD, CIAT, 1985. p.61-78.

GÁLVEZ, G.E.; GALINDO, J.; ALVAREZ, G. Defoliación artificial para estimar perdidas por daños foliares en frijol (Phaseolus vulgaris L.). Turrialba, v.27, n.2, p.143146, 1977.

GIANASI, L. Patossistema feijoeiro - antracnose: efeito do trifenil acetato de estanho no crescimento do hospedeiro e no progresso da doença. Ciência e Agrotecnologia, v.26, n.2, p.309-317, 2002.

HOHMANN, C.L.; CARVALHO, S.M. Efeito da redução foliar no rendimento do feijoeiro (Phaseolus vulagaris L.). In: REUNIÃO NACIONAL DE PESQUISA DE FEIJÃO, 1., 1982, Goiânia, GO. Resumos. Goiânia: EMBRAPA/CNPAF, 1982. p.91-92.

MARTINS FILHO, S.; TAGLIAFERRE, C.; RANGEL, O.J.P.; SCHMILDT, E.R.; MARQUES, E.M.G. Interação genótipo $\mathrm{x}$ ambiente na avaliação do feijoeiro no estado do Espírito Santo. In: CONGRESSO BRASILEIRO DE MELHORAMENTO DE PLANTAS, 1., 2001, Goiânia, GO. Resumos. Goiânia: Embrapa, CNPFA-Embrapa, 2001. 1-CD-Rom.

MORAES, W.B.; MARTINS FILHO, S.; GARCIA, G.O.; CAETANO, S. de P.; MORAES, W.B. Avaliação de linhagens promissoras de feijoeiro tolerantes à seca. Revista Brasileira de Ciências Agrárias. v.3, n.2, p.121-125, 2008.

MOURA, G. de M. Efeito do desfolhamento no rendimento do feijoeiro. Pesquisa Agropecuária Brasileira, v.34, n.1, p.57-62, 1999. 
MOURA, G. de M.A.; MESQUITA, J.H. de L. Influência do desfolhamento artificial no rendimento de grãos do feijoeiro (Phaseolus vulgaris L.), no Acre. In: REUNIÃO NACIONAL DE PESQUISA DE FEIJÃO, 1., 1982, Goiânia, GO. Resumos. Goiânia: EMBRAPA/CNPAF, 1982. p.124-127.

PETERSON, R.K.D.; HIGLEY, L.G.; HAILE, F.J.;

BARRIGOSSI, J.A.F. Mexican bean beetle (Coleoptera: Coccinellidae) injury affects photosynthesis of Glycine max and Phaseolus vulgaris. Environmental Entomology, v.27, n.2, p.373-381, 1998.

PRATISSOLI, D.; SCHIMLDT, E.R.; REIS, E.F. dos; THULER, R.T. Influência de desfolhas simuladas na produtividade e em outras características agronômicas do feijoeiro. Revista Ceres, v.48, n.275, p.17-24, 2001.

QUINTELA, E.D. Manejo Integrado de pragas do feijoeiro. In: KLUTHCOUSKI, J.; STONE, L.F.; AIDAR, H. (Ed.). Fundamentos para uma agricultura sustentável, com ênfase na cultura do feijoeiro. Santo Antônio de Goiás: Embrapa Arroz e Feijão, 2009. p.289-308.

SCHAAFSMA, A.W.; ABLETT, G.R. Yield loss response of navy bean to partial or total defoliation. Journal of Production Agriculture, v.7, n.2, p.202-205, 1994. Cul- tura feijão..<http://www.seagri.ba.gov.br/Feijao. htm\#Aspectos\%20Gerais>. Acesso em: 26 jan. 2009.

SEDIYAMA, T.; PEREIRA, M.G.; SEDIYAMA, C.S.; GOMES, J.L.L. Cultura da soja: $1^{a}$ parte. Viçosa: UFV, 1985. 96p. (Boletim, 211).

SILVA, A.L. da; VELOSO, V. da R.S.; CRISPIM, C.M.P.; BRAZ, V.C.; SANTOS, L.P. dos; CARVALHO, M.P. de Avaliação do efeito de desfolha na cultura do feijoeiro (Phaseolus vulgaris L.). Pesquisa Agropecuária Tropical, v.33, n.2, p.83-87, 2003.

WATSON, D.J. Comparative physiological studies on the growth of field crops. I. Variation in net assimilation rate and leaf area between species and varieties, and within and between years. Annals of Botany, v.11, n.41, p.41-76, 1947.

XIA, M.Z. Effects of bean leaves in different positions on the yield and photosynthetic compensation after defoliation. Journal of Agronomy and Crop Science, v.171, n.2, p.145-152, 1993.

Recebido em 30/4/09

Aceito em 14/7/10 